\title{
Synthesis and Characterization of Vanadium Doped Zinc Oxide Thick Film for Chemical Sensor Application
}

\author{
Rayees Ahmad Zargar, ${ }^{1}$ Manju Arora, ${ }^{2}$ Masroor Ahmad, ${ }^{3}$ and Aurangzeb Khurram Hafiz ${ }^{1}$ \\ ${ }^{1}$ Department of Physics, Jamia Millia Islamia, New Delhi 110025, India \\ ${ }^{2}$ CSIR-National Physical Laboratory, Dr. K.S. Krishnan Marg, New Delhi 110012, India \\ ${ }^{3}$ Superconductivity Research Laboratory, Department of Physics, Barkatullah University, Bhopal 462026, India \\ Correspondence should be addressed to Manju Arora; marora@nplindia.org
}

Received 14 June 2015; Revised 22 September 2015; Accepted 7 October 2015

Academic Editor: Achim Trampert

Copyright (C) 2015 Rayees Ahmad Zargar et al. This is an open access article distributed under the Creative Commons Attribution License, which permits unrestricted use, distribution, and reproduction in any medium, provided the original work is properly cited.

\begin{abstract}
Zinc oxide and vanadium pentoxide nanoparticles derived by chemical coprecipitation route were used to cast $\mathrm{Zn}_{0.96} \mathrm{~V}_{0.04} \mathrm{O}$ thick film by screen printing method. The structural, morphological, optical, and electrical properties of the film were characterized by powder XRD, SEM, Raman, UV-VIS, and DC conductivity techniques. XRD pattern, SEM image, and Raman spectrum of the film confirm the single phase formation of Wurtzite structure with preferential orientation along [101] plane, minor variation in lattice parameters, and vanadium ions substitution at zinc sites. $\mathrm{Zn}_{0.96} \mathrm{~V}_{0.04} \mathrm{O}$ pellet has been used for sensing ammonia vapor concentrations in $20-50^{\circ} \mathrm{C}$ temperature range which exhibits maximum responsiveness and sensitivity at $30^{\circ} \mathrm{C}$. The minor variations in resistance are observed with ammonia vapor concentration. The adsorption of ammonia vapors through weak hydrogen bonding and its insertion into lattice by nitrogen lone pairs donation at vacant/defect sites in lattice caused by vanadium doping are considered to explain gas sensing mechanism.
\end{abstract}

\section{Introduction}

The metal oxide semiconductors have been extensively explored by researchers in pure and doped form. Doping introduces remarkable changes in the structural, optical, electrical, magnetic, and semiconducting properties which encourages their use in various applications, namely, sensors and piezoelectric, photovoltaic, electrooptic, and microelectromechanical devices [1-5]. Zinc oxide $(\mathrm{ZnO})$ is a multifunctional material with wide band gap (3.37 ev), n-type hexagonal structured, high electron mobility, large piezoelectric constants, high nonlinear optical coefficients, radiation hardness, biocompatibility, and large $60 \mathrm{meV}$ exciton binding energy characteristics. It is suitable for small wavelength optoelectronic devices. The stability of $\mathrm{ZnO}$ film has been found to be an alternative substitute to tin oxide and indium tin oxide films whose electrical and optical properties degrade at high temperatures. Nowadays pure and mixed oxide films of $\mathrm{CuO}$, $\mathrm{Al}_{2} \mathrm{O}_{3}, \mathrm{CdO}, \mathrm{NiO}$, and $\mathrm{SnO}_{2}$ are used in various photonic devices by optimizing their band gap and activation energy.
The doping of $\mathrm{ZnO}$ with vanadium caused marked changes in electrical and magnetic properties [6,7]. Single phase vanadyl doped $\mathrm{ZnO}$ belongs to the diluted magnetic semiconductor (DMS) category. The ferromagnetism in $\mathrm{V}$ doped $\mathrm{ZnO}$ was predicted both theoretically and experimentally $[8,9]$. The enhancement in electrical properties of $\mathrm{V}$ doped $\mathrm{ZnO}$ films has been reported by Jin et al. [10] due to increased electron concentration resulting from the electric charge compensation by the substitution of vanadium ions at $\mathrm{Zn}^{2+}$ ions site in $\mathrm{ZnO}$. In addition to the better ferromagnetic and electrical properties, $\mathrm{V}$ doped $\mathrm{ZnO}$ also exhibits ferroelectricity at and above ambient temperature $[6,7]$. The R\&D work on vanadium doped zinc oxide $\left(\mathrm{Zn}_{1-x} \mathrm{~V}_{x} \mathrm{O}\right)$ is still going on to explore its utilization in more promising applications in the field of optoelectronics, sensors, and ferroelectric memory devices.

Doped $\mathrm{ZnO}$ nanoparticles were synthesized by different physical and chemical methods such as spray pyrolysis, RF sputtering, electrochemical deposition, chemical vapor deposition, chemical coprecipitation, and sol-gel [11-22]. Out 
of these, the simple and economic chemical coprecipitation method has been adopted for the synthesis of zinc oxide and vanadium pentoxide nanoparticles from zinc acetate dihydrate and ammonium metavanadate reactants. The thick films were cast from prepared $\mathrm{ZnO}$ and $\mathrm{V}_{2} \mathrm{O}_{5}$ nanoparticles in 96 wt.\%: 4 wt.\% ratio, respectively, to cast $\mathrm{Zn}_{0.96} \mathrm{~V}_{0.04} \mathrm{O}$ thick films by screen printing method, and characterized for their structural, morphological, and optical properties. This film is tested for ammonia vapor sensor application at different operating temperature and ammonia concentration. The ammonia vapor sensing has been chosen because it is most extensively used in the chemical, textile, and pharmaceutical industries worldwide. Its toxic vapor causes many health issues and even death on long exposure.

\section{Experimental Measurements}

2.1. Materials Used. The as-obtained Sigma Aldrich zinc acetate dehydrate, ammonium metavanadate, and sodium hydroxide analytical reagent (AR) grade chemicals without any further purification are used for synthesis of nanoparticles (NPs). AR grade anhydrous zinc chloride and ethylene glycol, Merck, India, Make, were used as adhesive and binding agents in screen printing of thick film. Analytical regent (LR) grade ammonia solution of Merck, India, was used for ammonia vapor sensing.

\subsection{Synthesis of Vanadium Doped Zinc Oxide Thick Films.} First, $\mathrm{ZnO}$ and $\mathrm{V}_{2} \mathrm{O}_{5}$ nanoparticles were prepared by chemical coprecipitation route by using zinc acetate dihydrate and ammonium metavanadate as reactants. $1.00 \mathrm{M} \mathrm{NaOH}$ was added to $0.5 \mathrm{M}$ zinc acetate dehydrate and $0.5 \mathrm{M}$ ammonium metavanadate aqueous solutions separately for precipitating zinc oxyhydroxide and vanadyl oxyhydroxide. These precipitated nanoparticles were filtered and dried at $70^{\circ} \mathrm{C}$ and then sintered at $450^{\circ} \mathrm{C}$ to obtain to oxides of respective nanoparticles. Thick film paste was prepared by thoroughly mixing 4 wt.\% $\mathrm{V}_{2} \mathrm{O}_{5}$ NPs with 96 wt.\% $\mathrm{ZnO} \mathrm{NPs}$ to produce $\mathrm{Zn}_{0.96} \mathrm{~V}_{0.04} \mathrm{O}$ composition with anhydrous $\mathrm{ZnCl}_{2}$ as an adhesive agent and ethylene glycol as a binder. The prepared paste was used for screen printing on precleaned glass substrates. The details of film casting procedure are described in $[19,20]$ and setup schematic is shown in Figure 1. The as-deposited films were dried at $60^{\circ} \mathrm{C}$ for two hours and then further annealed in a muffle furnace in air at $550^{\circ} \mathrm{C}$ for ten minutes for proper adherence, stability, and decomposition of organic and inorganic compounds for achieving the desired stoichiometry of vanadium doped zinc oxide film. The thickness of the film $5 \mu \mathrm{m}$ was measured by employing a profilometer (Surftest SJ-301).

2.3. Characterization Techniques Used. X-ray diffraction pattern was recorded on advanced Rigaku diffractometer in $2 \theta$ range of $10^{\circ}-80^{\circ}$ using $\mathrm{Cu}-\mathrm{K} \alpha \mathrm{X}$-ray radiation source. The surface morphological information was derived by using scanning electron microscope (SEM, Leo-440, UK) for recording micrographs. Perkin Elmer Fourier Transform

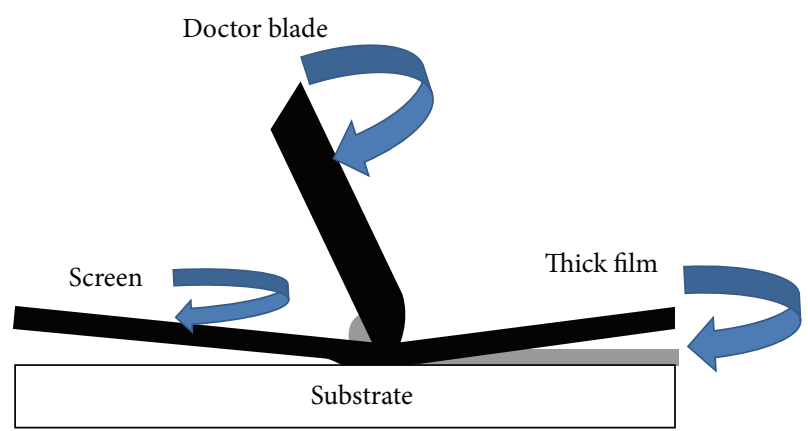

FIGURE 1: Thick film casting by screen printing setup schematic.

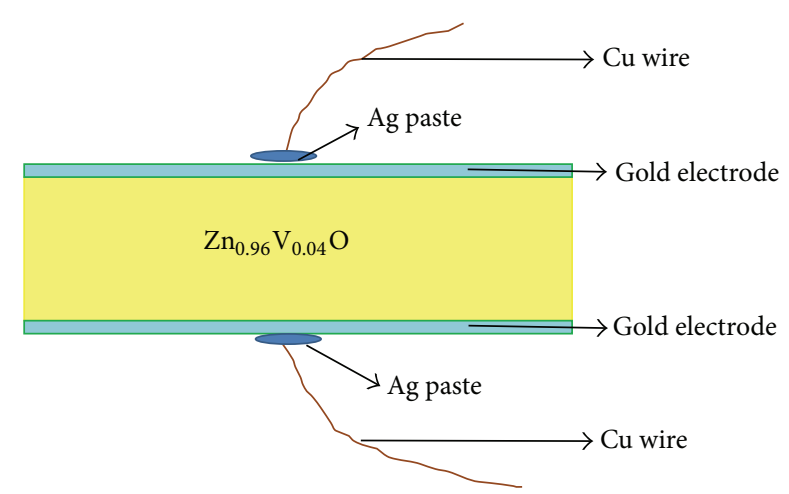

Figure 2: Schematic of $\mathrm{Zn}_{0.96} \mathrm{~V}_{0.04} \mathrm{O}$ pellet based sensing element.

Raman spectrometer was used for recording Raman spectrum of the as-deposited film in $3500-100 \mathrm{~cm}^{-1}$ region at room temperature. The optical transmission spectrum was measured on Hitachi Make UV-VIS spectrometer-3900 in the 350-650 nm range. DC resistivity measurement was done by using standard four-probe technique.

2.4. Ammonia Vapor Sensor Setup. For ammonia vapor detection, the sensing element is shown in Figure 2 which consists of $5 \mathrm{~mm} \times 3 \mathrm{~mm} \times 1 \mathrm{~mm} \mathrm{Zn}_{0.96} \mathrm{~V}_{0.04} \mathrm{O}$ pellet with gold evaporated electrodes on the edges. For electrical connection, copper wires were pasted by silver paste. It acts like a parallel plate condenser as shown in the following schematic diagram.

A micro pipette was used to inject ammonia (50, 75, $100,125$, and $150 \mu \mathrm{L})$ or $(45,67.5,90,112.5$, and $135 \mathrm{ppm})$ into a sealed glass chamber with a syringe through the inlet. The resistance of the film was measured before and after being exposed to ammonia vapors using Keithley 2000 multimeter. The series of experiments were carried out to check repeatability of results. Further, similar measurements were done at different temperatures using a constant temperature water bath to check the responsiveness of sensor at different temperatures from $20^{\circ} \mathrm{C}$ to $50^{\circ} \mathrm{C}$.

\section{Results and Discussion}

In doped nanocrystalline materials, the variation in electrical, electronic, optical, and magnetic properties generally resulted from modification in composition and lattice network by 


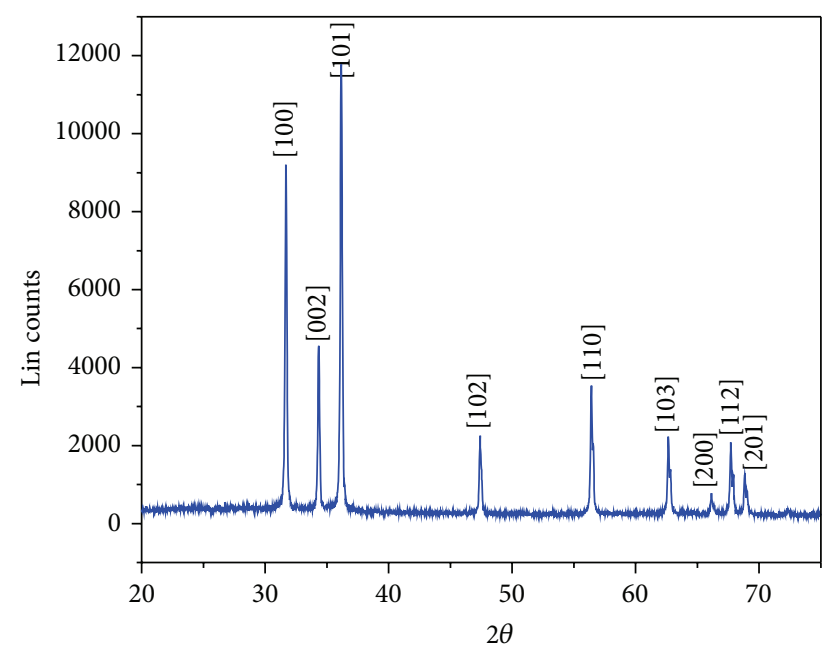

FIgURE 3: XRD pattern of $\mathrm{Zn}_{0.96} \mathrm{~V}_{0.04} \mathrm{O}$ thick film.

dopant atoms/molecules in the host crystal lattice. The formation vanadium doped $\mathrm{ZnO}$ thick film was confirmed from powder X-ray diffraction (XRD) pattern as shown in Figure 3 with peaks plane indexing. This shows the polycrystalline nature of film with preferential orientation along (101) plane, wurtzite crystal structure, and lattice parameters $a=3.2601 \AA$ and $c=5.2113 \AA$ (JCPDS number 36-1451). As there is no other crystalline phase seen in the XRD pattern, hence this indicates the high purity of the as-synthesized nanoparticles. The lattice parameter calculations [21,22] reveal that $c$ lattice parameter value of $\mathrm{V}: \mathrm{ZnO}$ film increases linearly from 5.18 (for pure $\mathrm{ZnO}$ ) to $5.21 \AA$ (for $4 \mathrm{wt} . \% \mathrm{~V}$ doped $\mathrm{ZnO}$ thick film). This increase in the $c$ parameter value confirms the substitution of bigger $\mathrm{V}^{2+} / \mathrm{V}^{5+}$ ions (ionic radius $0.93 \AA / 0.88 \AA$ ) in the hexagonal wurtzite $\mathrm{ZnO}$ structure at smaller $\mathrm{Zn}$ ions (ionic radius $0.74 \AA$ ). This may lead to an increase in the lattice parameter values. The average crystallites size is $\sim 30 \mathrm{~nm}$ and lattice strain: 0.0005 .

SEM image recorded at $20 \mathrm{kV}$ energy and $\times 33,000 \mathrm{mag}$ nification exhibits the uniform deposition of films uniformly distributed large sized grains consisting of hexagonal shaped tips as marked in image, agglomeration of particles of rectangular to hexagon shaped ones. At some regions the fusion of agglomerated tubes is also observed. The recorded micrograph is presented in Figure 4.

This micrograph showed that this small concentration of $\mathrm{V}^{2+}$ ions doping in $\mathrm{ZnO}$ lattice causes growth of large sized grains which results in porous surface. The bigger ionic radii of vanadium ions distort crystal structure due to ionic radii mismatch which increases grains/particles growth activity of $\mathrm{ZnO}$ and formation of bigger particles [23].

$\mathrm{ZnO}$ belongs to the space group $C_{6 v}{ }^{4}$ with two molecules per unit cell in which $A_{1}$ and $E_{1}$ branches have both Raman and infrared active modes and $E_{2}$ branches are only Raman active, whereas $B_{1}$ branches have both Raman and infrared inactive (silent) modes. The nonpolar $E_{2}$ phonon modes have two frequencies: $E_{2}$ (high) is associated with the vibration of oxygen atoms and $E_{2}$ (low) is associated with the $\mathrm{Zn}$

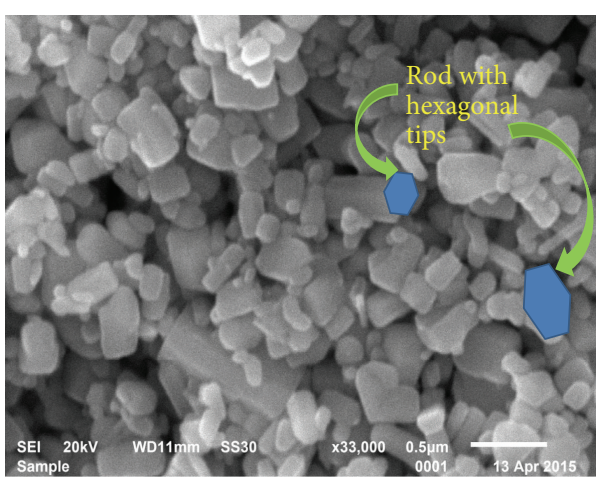

FIgURE 4: SEM micrograph of $\mathrm{Zn}_{0.96} \mathrm{~V}_{0.04} \mathrm{O}$ thick film.

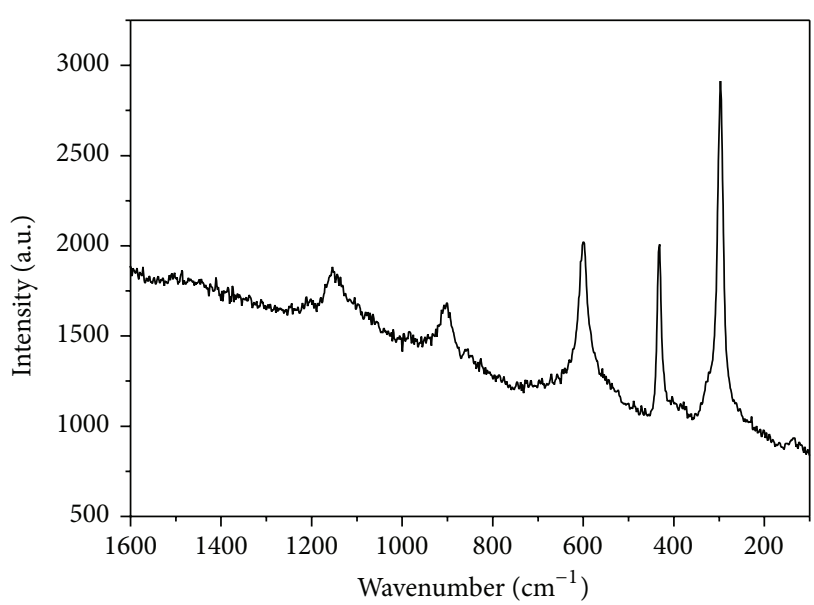

Figure 5: Raman spectrum of $\mathrm{Zn}_{0.96} \mathrm{~V}_{0.04} \mathrm{O}$ thick film in 1600 $100 \mathrm{~cm}^{-1}$ region.

sublattice. Raman spectrum in Figure 5 of $\mathrm{V}$ doped $\mathrm{ZnO}$ thick film showed peaks at 296, 435, 578, 908, and $1156 \mathrm{~cm}^{-1}$. In low wavenumber range, a very strong peak observed at $296 \mathrm{~cm}^{-1}$ is attributed to V-O lattice vibration mode [24], while the peak at $435 \mathrm{~cm}^{-1}$ is attributed to $\mathrm{ZnO} E_{2}$ (high) phonon mode. The peaks at 578 and $1156 \mathrm{~cm}^{-1}$ are assigned as $E_{1}(\mathrm{LO})$ and $2 E_{1}(\mathrm{LO})$ modes, respectively. The medium intensity peak at $908 \mathrm{~cm}^{-1}$ in $1000-800 \mathrm{~cm}^{-1}$ region arises from the $\mathrm{Zn}-\mathrm{O}-\mathrm{V}$ lattice vibration. The deviation in observed peak positions as compared to pure $\mathrm{ZnO}$ has been explained in terms of the difference in masses and ionic radii of the $\mathrm{V}$ and $\mathrm{Zn}$ ions in lattice. The presence of strong $E_{2}$ mode and weak $E_{1}(\mathrm{LO})$ mode confirms good crystal quality with less structural defects and impurities.

Figure 6 transmittance spectrum of $\mathrm{Zn}_{0.96} \mathrm{~V}_{0.04} \mathrm{O}$ film measured in $200-700 \mathrm{~nm}$ region shows that films are highly visible with $81 \%$ transmission value.

The energy band gap value is reflected in the inset of Figure 6 which comes out to be $3.21 \mathrm{eV}$, that is, less than pure $\mathrm{ZnO}(3.37 \mathrm{eV})$. The band gap energy of $\mathrm{V}_{2} \mathrm{O}_{5}$ is $2.3 \mathrm{eV}$ and $\mathrm{ZnO}$ is $3.37 \mathrm{eV}$; when $\mathrm{V}_{2} \mathrm{O}_{5}$ is doped in $\mathrm{ZnO}$, alloy is formed which causes decrease in band gap. So the band gap 


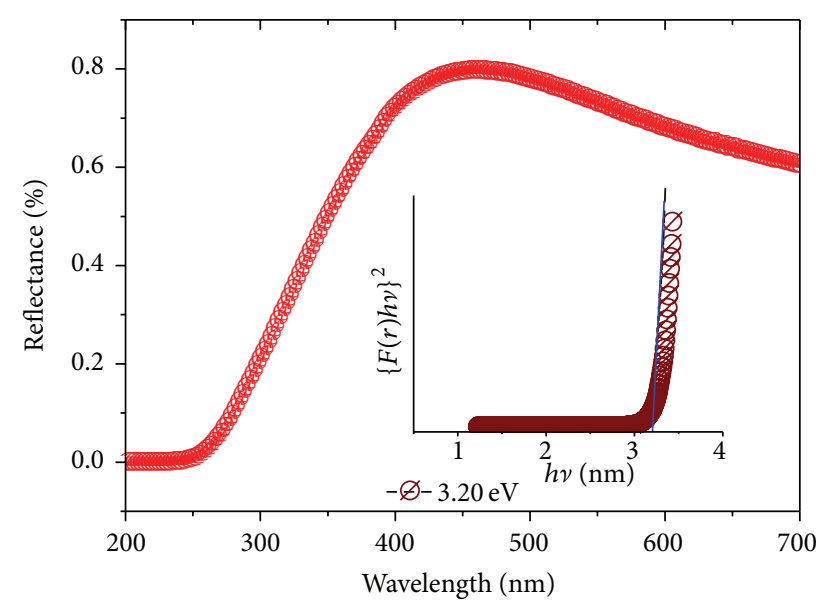

FIGURE 6: Optical reflection spectrum of $\mathrm{Zn}_{0.96} \mathrm{~V}_{0.04} \mathrm{O}$ thick film in 200-700 nm region.

narrowing in vanadium doping in $\mathrm{ZnO}$ lattice is an outcome of the alloying effect between $\mathrm{V}_{2} \mathrm{O}_{5}$ and $\mathrm{ZnO}$.

DC electrical conductivity measurements have been carried out in the temperature range $300-400 \mathrm{~K}$. The electrical resistivity $(\rho)$ was calculated by using [25]

$$
\rho=\frac{\pi t}{\ln 2}\left(\frac{V}{I}\right)
$$

where $\rho$ is the resistivity $(\Omega-\mathrm{cm}), t$ is the sample thickness (cm), $V$ is the applied voltage, and $I$ is the source current (A). The temperature dependency of the DC resistivity can be shown by the well-known Arrhenius equation [26].

Micheletti and Mark [27] estimated the intergranular barrier height $\left(\varphi_{b}\right)$ from the following equation:

$$
\mu=\mu_{0} \exp \left(-\frac{\varphi_{b}}{K T}\right)
$$

where all the terms have their usual meanings. The value of $\left(\varphi_{b}\right)$ obtained from plot Figure $7 \log (\rho)$ versus $1 / T$ is $0.65 \mathrm{eV}$. Charge carrier mobility $\mu$ is determined from the relation given in

$$
\mu=\frac{\sigma}{n e}
$$

where $n$ is electron density and $\sigma$ is the conductivity.

It implies the semiconducting nature of the sample because conductivity increases with increase in operating temperature due to increase of electron carriers.

3.1. Ammonia Vapor Sensing Mechanism. Ammonia vapor sensing is considered as a surface adsorption phenomenon of gas-solid interactions and the electrical conductivity at ambient temperature. In the adsorption process, ammonia vapors are chemically adsorbed on the active sites which gradually form the stable hydrogen bond stabilized chemisorbed $\mathrm{NH}_{3}$ group on the surface. When this first layer is formed then physical adsorption of ammonia vapors takes place as shown in Figure 8. The chemical absorption of

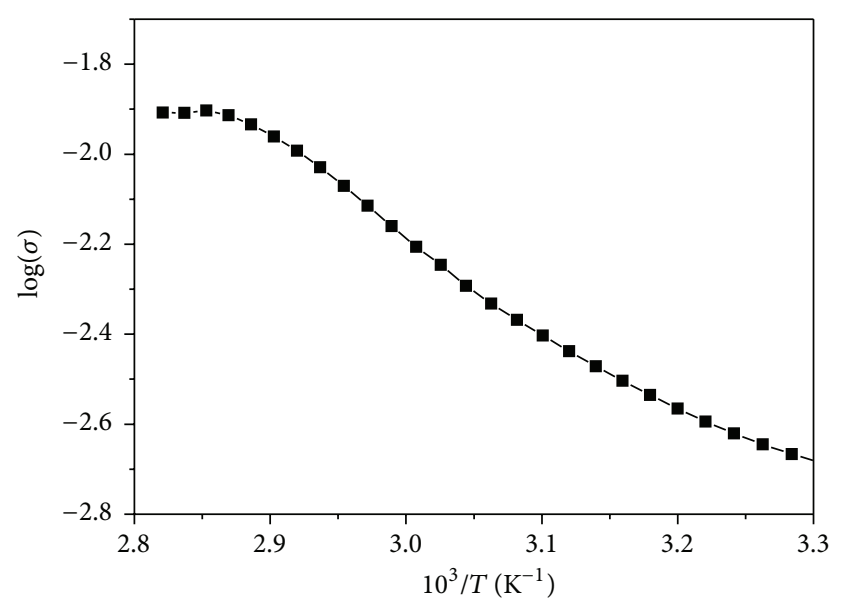

Figure 7: $1000 / T$ versus $\log (\sigma)$ of $\mathrm{Zn}_{0.96} \mathrm{~V}_{0.04} \mathrm{O}$ thick film.

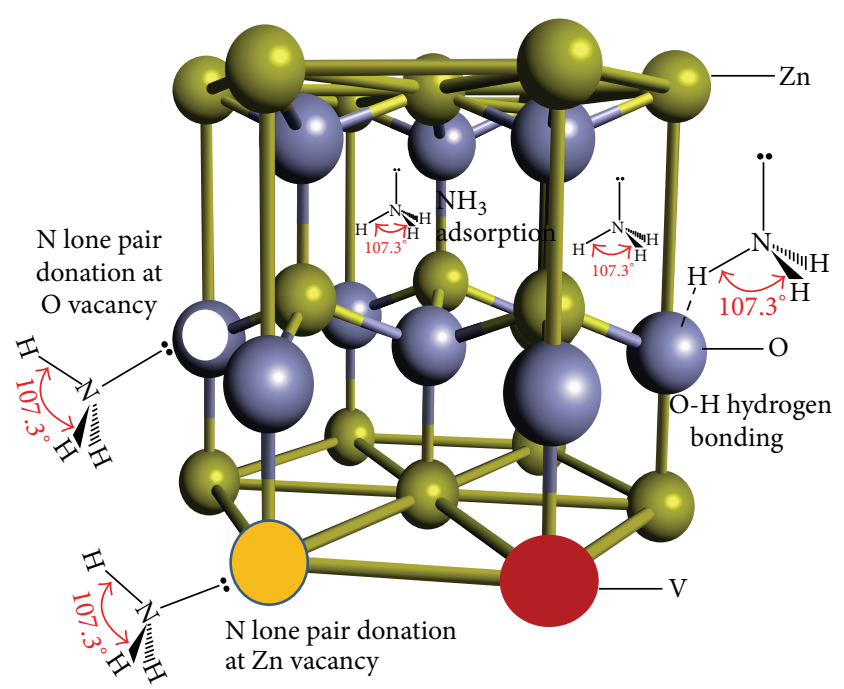

FIGURE 8: Chemisorption and adsorption of ammonia vapors on $\mathrm{Zn}_{0.96} \mathrm{~V}_{0.04} \mathrm{O}$ thick film.

ammonia vapors takes place between $\mathrm{ZnO}(\mathrm{O})$ and ammonia $(\mathrm{H})$ via weak hydrogen and nitrogen lone pair donation at oxygen vacancy/Zn sites. These inherent vacancies are formed in $\mathrm{ZnO}$ lattice during growth process. Ammonia gas is physically adsorbed on the surface pores of film. The high electrostatic field in the chemisorbed $\mathrm{OH}$ layer and the proton conduction takes place in the physisorbed layers. The condensation of ammonia vapor takes place in the mesopores and predominates in $30^{\circ} \mathrm{C}$ measurements. These results are in agreement with the resistance measurements. Vanadium doped zinc oxide nanoparticles exhibit enhancement in ammonia vapor sensing sensitivity and responsiveness with increase in ammonia vapor concentration. The change in electrical resistance has been used as the measure of ammonia vapor response at different temperatures.

Vanadium doped zinc oxide pellet prepared from nanoparticles with gold evaporated electrodes on the surface was used as sensing element for ammonia vapor detection in the laboratory. These nanostructure based sensors are 


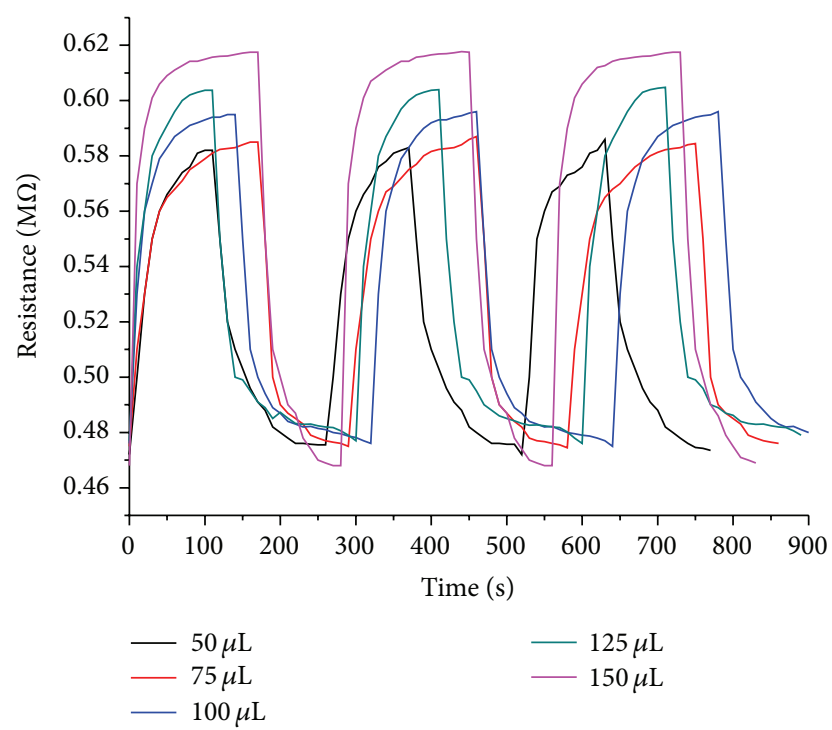

Figure 9: Resistance $\left(\mathrm{M} \Omega\right.$ ) versus time (sec.) at $30^{\circ} \mathrm{C}$ for $50,75,100$, 125 , and $150 \mu \mathrm{L}$ concentration of ammonia solution.

superior as compared to conventional gas sensors due to high sensitivity, selectivity, fast response, and recovery due to large number of active centers. In this work, ammonia vapors are sensed by vanadium doped zinc oxide sensing element in $20^{\circ} \mathrm{C}$ to $50^{\circ} \mathrm{C}$ at an interval of $5^{\circ} \mathrm{C}$. The response and recovery curve of $\mathrm{Zn}_{0.96} \mathrm{~V}_{0.04} \mathrm{O}$ thick film based semiconductor gas sensor at $30^{\circ} \mathrm{C}$ operating temperature under ammonia vapor concentration of $50,75,100,125$, and $150 \mu \mathrm{L}$ is presented in Figure 9. It is seen that the sensor resistance is higher in ammonia vapor atmosphere than in air. The sensor resistance decreases as the operating temperature increases.

In our studies the largest resistance increase was observed at $30^{\circ} \mathrm{C}$. On varying ammonia vapor concentration, the resistance varies slightly in a particular temperature operating range.

The quality of a gas sensor, responsiveness, sensitivity, and response time are the important parameters. The responsiveness $R_{S}$ is defined as $R_{S}=\left(R_{f}-R_{o}\right) / R_{o}$ where $R_{f}$ is the electrical resistance of the sensor in air and $R_{o}$ is its resistance in ethanol vapor. The sensitivity of sensor is defined as $R_{f} / R_{o}$. The response time is defined as the time required for the sample resistance variation to reach $90 \%$ of equilibrium value following a step increase in the concentration of the testing gas. The resistance, responsiveness sensitivity, and response time of vanadium doped zinc oxide based ethanol vapor sensor for $50,75,100,125$, and $150 \mu \mathrm{L}$ concentration of ammonia at $30^{\circ} \mathrm{C}$ are obtained from the response and recovery curves listed in Table 1.

Similarly, resistance, responsiveness, sensitivity, and response time of vanadium doped zinc oxide based ammonia vapor sensor are obtained for other temperatures and concentrations from the response and recovery curves. These results show that responsiveness, sensitivity, and time constant are practically constant with small deviations. This work reports the use of vanadium doped zinc oxide films as sensing element for the detection of ammonia vapor. The
TABLE 1

\begin{tabular}{lcccc}
\hline$R_{o}$ & $R_{f}$ & $\begin{array}{c}R_{s} \\
\left(R_{f}-R_{o}\right) / R_{o}\end{array}$ & $\begin{array}{c}\text { Sensitivity } \\
\left(R_{f} / R_{o}\right)\end{array}$ & $\begin{array}{c}\text { Response } \\
\text { time }\left(\tau_{90}\right)\end{array}$ \\
\hline 0.547 & 0.600 & 0.0969 & 1.0969 & 16 \\
0.543 & 0.602 & 0.1087 & 1.1087 & 11 \\
0.555 & 0.627 & 0.1297 & 1.1297 & 42 \\
0.548 & 0.633 & 0.1551 & 1.1551 & 25 \\
0.566 & 0.650 & 0.1484 & 1.1935 & 37 \\
\hline
\end{tabular}

sensing mechanism is the interaction of ammonia vapors on the surface of vanadium doped zinc oxide nanoparticles via weak hydrogen bonding through hydrogen and nitrogen lone pair donation at zinc/oxygen vacant sites as shown in Figure 8. The substitution of bigger sized $\mathrm{V}^{2+}$ ions at $\mathrm{Zn}^{2+}$ site in $\mathrm{ZnO}$ lattice may be the reason for resistance increase during ammonia vapor sensing.

\section{Conclusion}

In the present work, zinc oxide and vanadium oxide nanoparticles were prepared by chemical coprecipitation route. The thick films from these as-synthesized nanoparticles were cast by simple, cost effective screen printing technique followed by drying and sintering of the film at $550^{\circ} \mathrm{C}$ temperature. The structural, optical, and morphological characteristics of these films were investigated. The ammonia vapor sensing properties of sample in the rectangular pellet form with different concentrations and temperature of ammonia vapors were studied. The responsiveness, sensitivity, and response time of the sensor were calculated from their response and recovery curves which show minor variations at a particular temperature with concentration of ammonia vapors. This material is found to be suitable candidate for ammonia vapor sensor in the selected temperature range.

\section{Conflict of Interests}

The authors declare that there is no conflict of interests regarding the publication of this paper.

\section{Acknowledgment}

Rayees Ahmad Zargar is thankful to the CSIR-NPL, New Delhi, for giving permission to use characterization facilities required for analysis.

\section{References}

[1] C.-L. Hsu and S.-J. Chang, "Doped ZnO 1D nanostructures: synthesis, properties, and photodetector application," Small, vol. 10, no. 22, pp. 4562-4585, 2014.

[2] I. G. Dimitrov, A. O. Dikovska, P. A. Atanasov, T. R. Stoyanchov, and $\mathrm{T}$. Vasilev, "Al doped $\mathrm{ZnO}$ thin films for gas sensor application," Journal of Physics: Conference Series, vol. 113, no. 1, Article ID 012044, 5 pages, 2008. 
[3] M. L. Grilli, A. Sytchkova, S. Boycheva, and A. Piegari, "Transparent and conductive Al-doped $\mathrm{ZnO}$ films for solar cells applications," Physica Status Solidi A: Applications and Materials Science, vol. 210, no. 4, pp. 748-754, 2013.

[4] K. Khun, Z. H. Ibupoto, C. O. Chey, J. Lu, O. Nur, and M. Willander, "Comparative study of $\mathrm{ZnO}$ nanorods and thin films for chemical and biosensing applications and the development of $\mathrm{ZnO}$ nanorods based potentiometric strontium ion sensor," Applied Surface Science, vol. 268, pp. 37-43, 2013.

[5] R. A. Zargar, S. Chackrabarti, S. Joseph, M. S. Khan, R. Husain, and A. Hafiz, "Synthesis and characterization of screen printed ZnO films for solar cell applications," Optik, vol. 126, no. 23, pp. 4171-4174, 2015.

[6] T. Naydenova, P. Atanasov, M. Koleva et al., "Influence of vanadium concentration on the microstructure and magnetic properties of V-doped $\mathrm{ZnO}$ thin films," Thin Solid Films, vol. 518, no. 19, pp. 5505-5508, 2010.

[7] E. Schlenker, A. Bakin, B. Postels et al., "Magnetic characterization of $\mathrm{ZnO}$ doped with vanadium," Superlattices and Microstructures, vol. 42, no. 1-6, pp. 236-241, 2007.

[8] K. Sato and H. Katayama-Yoshida, "First principles materials design for semiconductor spintronics," Semiconductor Science and Technology, vol. 17, no. 4, pp. 367-376, 2002.

[9] N. Tahir, S. T. Hussain, M. Usman, S. K. Hasanain, and A. Mumtaz, "Effect of vanadium doping on structural, magnetic and optical properties of $\mathrm{ZnO}$ nanoparticles," Applied Surface Science, vol. 255, no. 20, pp. 8506-8510, 2009.

[10] Z. Jin, M. Murakami, T. Fukumura et al., "Combinatorial laser MBE synthesis of $3 \mathrm{~d}$ ion doped epitaxial $\mathrm{ZnO}$ thin films," Journal of Crystal Growth, vol. 55, pp. 214-215, 2000.

[11] E. A. Meulenkamp, "Synthesis and growth of $\mathrm{ZnO}$ nanoparticles," Journal of Physical Chemistry B, vol. 102, no. 29, pp. 55665572, 1998.

[12] P. S. Kumar, A. D. Raj, D. Mangalaraj, and D. Nataraj, "Growth and characterization of $\mathrm{ZnO}$ nanostructured thin films by a two step chemical method," Applied Surface Science, vol. 255, no. 5, pp. 2382-2387, 2008.

[13] Z. Wang, H. Zhang, L. Zhang, J. Yuan, S. Yan, and C. Wang, "Low-temperature synthesis of $\mathrm{ZnO}$ nanoparticles by solidstate pyrolytic reaction," Nanotechnology, vol. 14, no. 1, pp. 11-15, 2003.

[14] S. C. Erwin, L. Zu, M. I. Haftel, A. L. Efros, T. A. Kennedy, and D. J. Norris, "Doping semiconductor nanocrystals," Nature, vol. 436, no. 7047, pp. 91-94, 2005.

[15] L. Wang and M. Muhammed, "Synthesis of zinc oxide nanoparticles with controlled morphology," Journal of Materials Chemistry, vol. 9, no. 11, pp. 2871-2878, 1999.

[16] S. Vijayalakshmi, S. Venkataraj, and R. Jayavel, "Characterization of cadmium doped zinc oxide $(\mathrm{Cd}: \mathrm{ZnO})$ thin films prepared by spray pyrolysis method," Journal of Physics D: Applied Physics, vol. 41, no. 24, Article ID 245403, 7 pages, 2008.

[17] S. Mondal and P. Mitra, "Preparation of cadmium-doped $\mathrm{ZnO}$ thin films by SILAR and their characterization," Bulletin of Materials Science, vol. 35, no. 5, pp. 751-757, 2012.

[18] J. A. Najim and J. M. Rozaiq, "Effect Cd doping on the structural and optical properties of $\mathrm{ZnO}$ thin films," International Letters of Chemistry, Physics and Astronomy, vol. 15, pp. 137-150, 2013.

[19] R. A. Zargar, S. U. Khan, M. S. Khan, M. Arora, and A. K. Hafiz, "Synthesis and characterization of screen printed $\mathrm{Zn}_{0.97} \mathrm{Cu}_{0.03} \mathrm{O}$ thick film for semiconductor device applications," Physics Research International, vol. 2014, Article ID 464809, 5 pages, 2014.
[20] R. A. Zargar, S. Chackrabarti, M. Shahabuddin, J. Kumar, M. Arora, and A. K. Hafiz, "Novel composites of $\mathrm{Zn}_{1-x} \mathrm{Cd}_{x} \mathrm{O}(x=$ $0,0.05,0.1)$ thick films for optoelectronic device application," Journal of Materials Science: Materials in Electronics, 2015.

[21] B. D. Cullity, Elements of X-Ray Diffraction, Addison-Wesley, Reading, Mass, USA, 1978.

[22] S. Mahamuni, K. Borgohain, B. S. Bendre, V. J. Leppert, and S. H. Risbud, "Spectroscopic and structural characterization of electrochemically grown $\mathrm{ZnO}$ quantum dots," Journal of Applied Physics, vol. 85, no. 5, pp. 2861-2865, 1999.

[23] H. Çolak and O. Türkoĝlu, "Synthesis, crystal structural and electrical conductivity properties of Fe-doped zinc oxide powders at high temperatures," Journal of Materials Science and Technology, vol. 28, no. 3, pp. 268-274, 2012.

[24] K. Samanta, P. Bhattacharya, R. S. Katiyar, W. Iwamoto, P. G. Pagliuso, and C. Rettori, "Raman scattering studies in dilute magnetic semiconductor $\mathrm{Zn}_{1-x} \mathrm{Co}_{x} \mathrm{O}$," Physical Review B, vol. 73, no. 24, Article ID 245213, 5 pages, 2006.

[25] J. Chan, Four-Point Probe Manual, EECS143, Micro Fabrication Technology, 1994, Modified by Paul Friedberg, 2002.

[26] P. K. Ghosh, R. Maity, and K. K. Chattopadhyay, "Electrical and optical properties of highly conducting CdO:F thin film deposited by sol-gel dip coating technique," Solar Energy Materials and Solar Cells, vol. 81, no. 2, pp. 279-289, 2004.

[27] F. B. Micheletti and P. Mark, "Effects of chemisorbed oxygen on the electrical properties of chemically sprayed cds thin films," Applied Physics Letters, vol. 10, no. 4, pp. 136-138, 1967. 

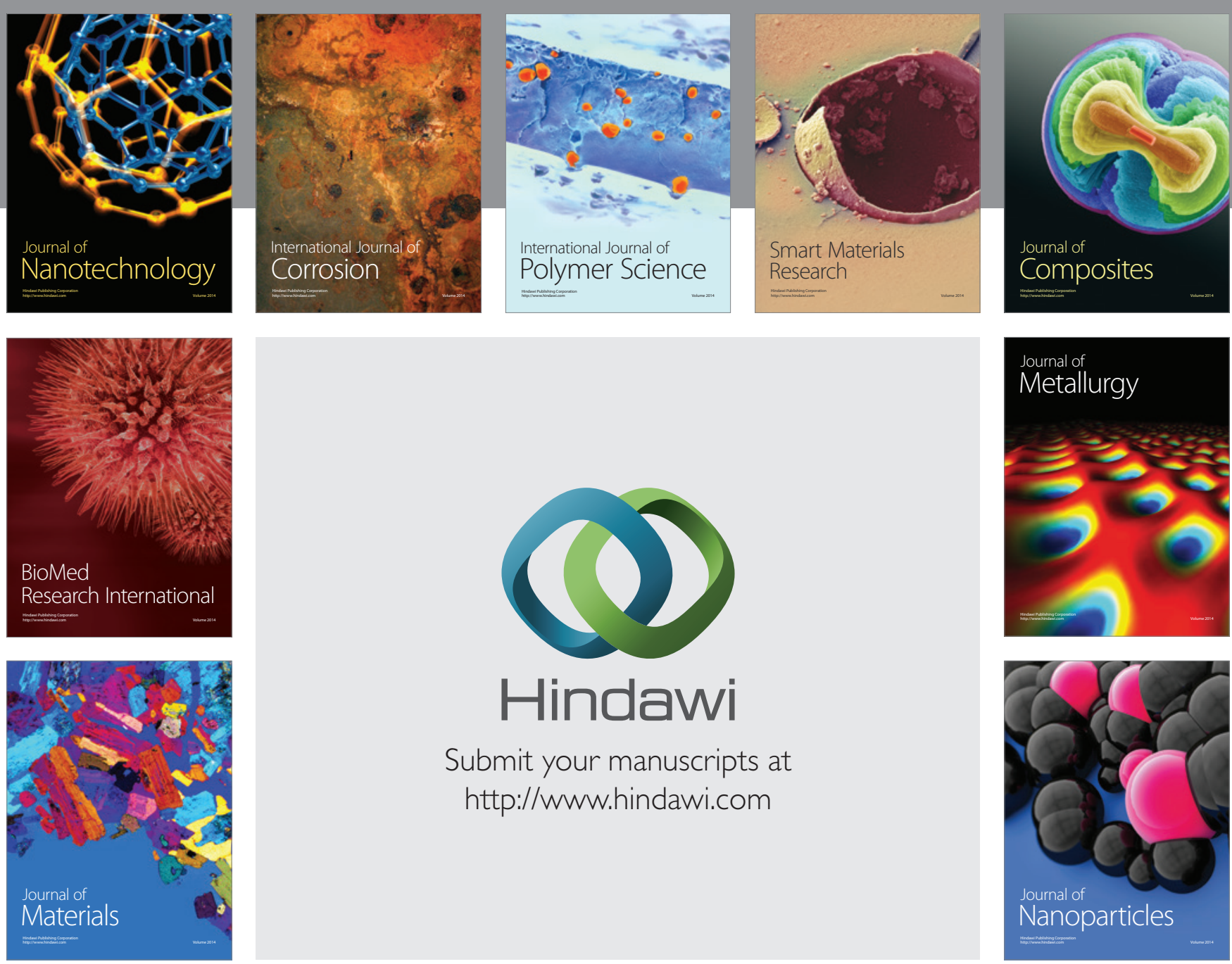

Submit your manuscripts at http://www.hindawi.com
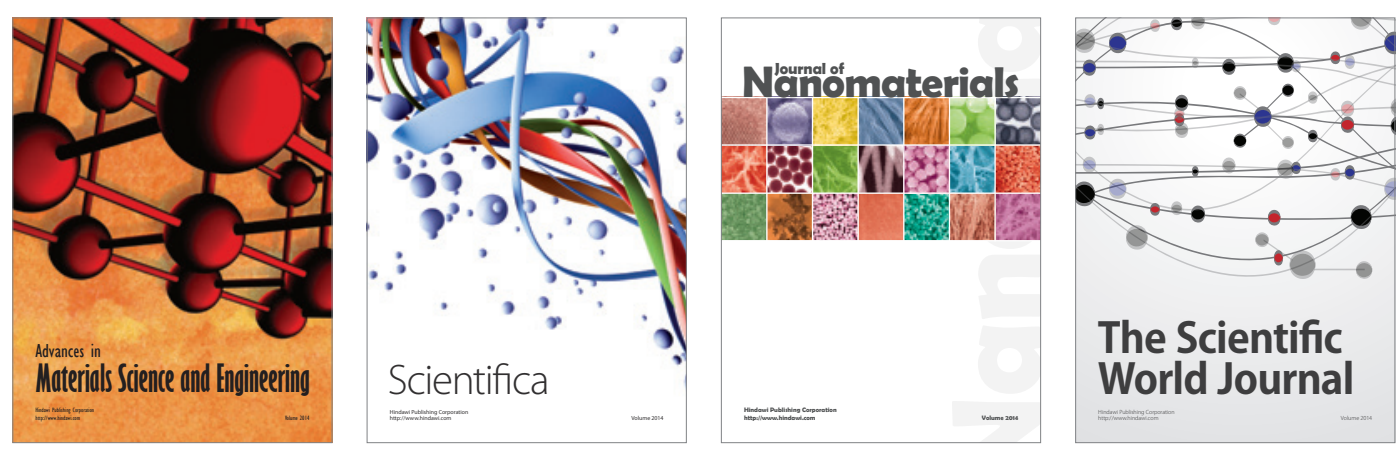

\section{The Scientific World Journal}
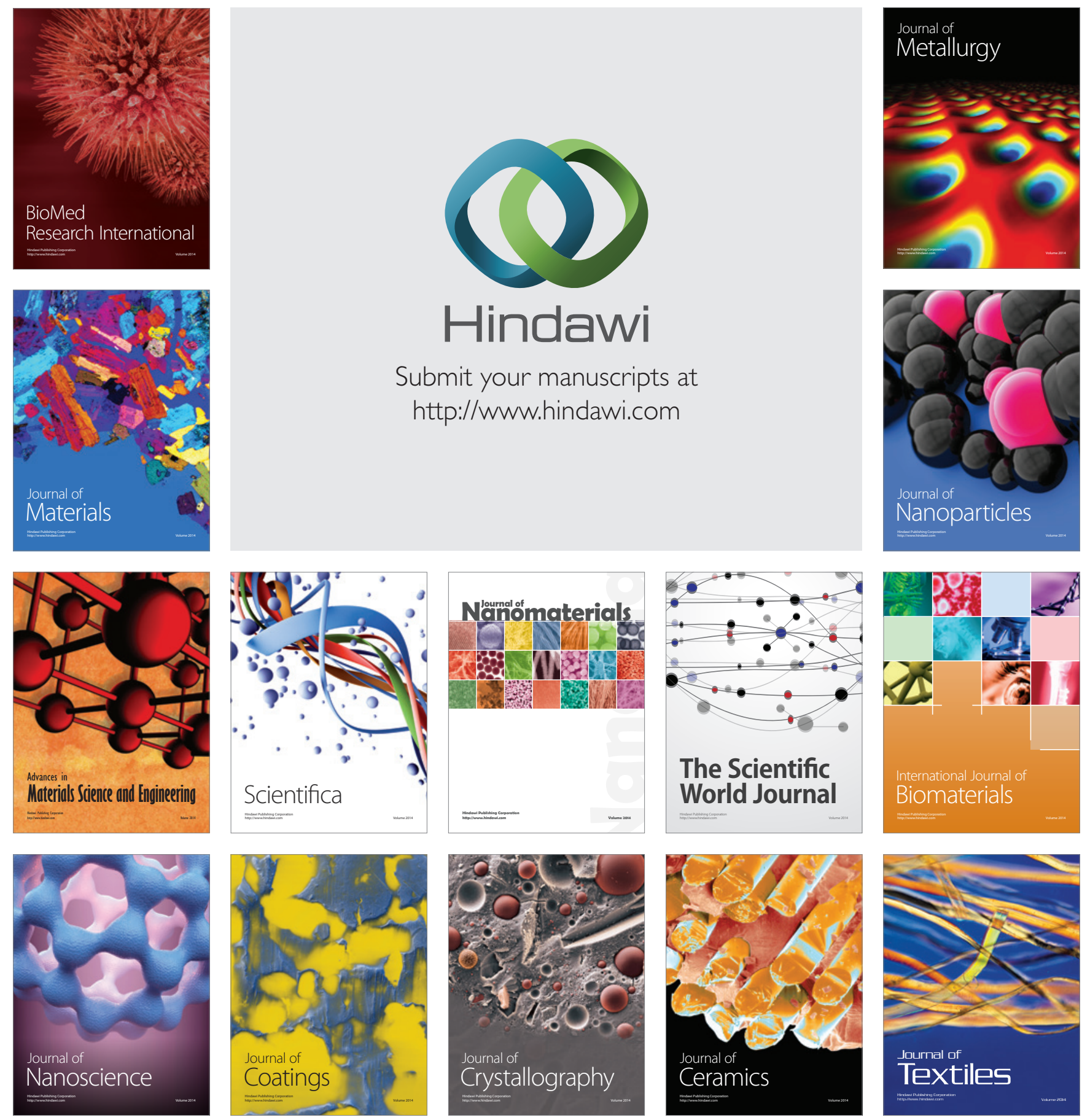